\title{
Estimation of genetic parameters and genetic change for stillbirth in Iranian Holstein cows: a comparison between linear and threshold models
}

\author{
Navid Ghavi Hossein-Zadeh \\ Department of Animal Science, Faculty of Agriculture, University of Guilan, Rasht, Iran, P. O. Box: 41635-1314 \\ e-mail:nhosseinzadeh@guilan.ac.ir
}

\begin{abstract}
Data on stillbirth from the Animal Breeding Center of Iran collected from January 1990 to December 2007 and comprising 668810 Holstein calving events from 2506 herds were analyzed. Linear and threshold animal and sire models were used to estimate genetic parameters and genetic trends for stillbirth in the first, second, and third parities. Mean incidence of stillbirth decreased from first to third parities: $23.7 \%, 22.1 \%$, and $21.8 \%$, respectively. Phenotypic rates of stillbirth decreased from 1993 to 1998 , for first, second and third calvings, and then increased from 1998 to 2007 for the first three parities. Direct heritability estimates of stillbirth for parities 1,2 and 3 ranged from 2.2 to $8.7 \%, 0.6$ to $5.1 \%$ and 0.1 to $3.8 \%$, respectively, and maternal heritability estimates of stillbirth for parities 1,2 and 3 ranged from 1.4 to $6.3 \%, 0.5$ to $4.2 \%$ and 0.08 to $2.0 \%$, respectively, using linear and threshold animal models. The threshold sire model estimates of heritabilities for stillbirth in this study were 0.021 to 0.071 , while the linear sire model estimates of heritabilities for stillbirth in the current study were from 0.003 to 0.021 over the parities. There was a slightly increasing genetic trend for stillbirth rate in parities 1 and 2 over time with the analysis of linear animal and linear sire models. There was a significant decreasing genetic trend for stillbirth rate in parity 1 and 3 over time with the analysis of threshold animal and threshold sire models, but the genetic trend for stillbirth rate in parity 2 with these models of analysis was significantly positive. The low estimates of heritability obtained in this study implied that much of the improvement in stillbirth could be attained by improvement of production environment rather than genetic selection.
\end{abstract}

Key words: dairy cow, genetic trend, linear model, stillbirth, threshold model

\section{Introduction}

Two general classes of phenotypes, continuous and discrete, are considered in animal breeding data. Many traits of importance, such as litter size, calving ease, disease resistance and stillbirth are measured on a discrete scale. Genetic evaluation methodology for categorical traits is different from that of continuous traits (Abdel-Azim and Berger 1999). Wright (1934) postulated that a linear variable underlies categorical traits and thresholds define which category is observed. Based on threshold concept, non-linear methods for sire evaluation have been described for categorical traits (Gianola 1982, Harville and Mee 1984, Gilmour et al. 1985). Stillbirth in dairy cattle is one of the functional traits that receives more and more attention due to its effects on the profitability of dairy production. During the last two decades the incidence of stillbirths for Holstein cattle has increased in several countries such as Denmark (Nielsen et al. 
Ghavi Hossein-Zadeh, N. Genetic parameters for stillbirth in dairy cows

2002), Sweden (Steinbock et al. 2003) and in the United States (Meyer et al. 2001a). Stillbirths in dairy cattle herds reduce the potential number of replacement heifers and reduce the revenue from bulls for fattening, but it is also an ethical problem related to animal welfare. Stillbirth has been shown to be heritable (Philipsson 1976, Weller et al. 1988, Luo et al. 1999) and this means that stillbirth is a potential trait to include in a breeding program, and, therefore, exact knowledge of genetic parameters for this trait is needed.

Trait definitions vary slightly between countries, with most defining stillbirths as those calves born dead or dying within $24 \mathrm{~h}$ of parturition (Philipsson et al. 1979), although Germany, and the United States include deaths within $48 \mathrm{~h}$ of birth (Berger et al. 1998). Breed differences play a role in perinatal mortality (Philipsson 1976, Thompson et al. 1981), and Rossoni et al. (2005) reported that $10 \%$ of Italian Brown Swiss calves did not suckle by the third meal offered postpartum, contributing to increased postnatal mortality. Incidence rates and heritabilities were similar when comparing parities across countries despite differences in trait definition, with the exception of Sweden (Steinbock et al. 2003). Many studies of genetic parameters of stillbirth have applied linear models (e.g., Luo et al. 1999, Meyer et al. 2001b, Jamrozik et al. 2005), or single-trait threshold models (e.g., Steinbock et al. 2003, Hansen et al. 2004 a,b). These authors found direct and maternal heritabilities between 0.04 and 0.07 for stillbirth.

In a review, Shook (1998) concluded that more genetic studies of calfhood diseases and mortality were needed. Extensive knowledge and analysis of the genetics of stillbirth are valuable for better understanding the biological background, monitoring cattle populations and possibly for providing a basis for selection. As focus shifts from selection of production traits to functional traits in the current breeding programs for dairy cows, genetic evaluation on traits as stillbirth would be valuable and essential. Although, the subject of this study has been investigated by other researchers, but the novel item in this study included the use of data set obtained from dairy herds in Iran. Linear models are currently applied for the genetic evaluation of stillbirth in other studies. Although, a threshold model (Gianola and Foulley 1983) may be a more valid model because it takes into account the categorical nature of these traits. Therefore, the first objective of this study was the estimation of heritabilities and genetic trends for stillbirth using linear and threshold animal and sire models in the first three lactations of Holstein dairy cows in Iran. The other objective was the comparison of estimates obtained by different linear and threshold models.

\section{Material and methods}

\section{Data set}

Calving records from the Animal Breeding Center of Iran, collected from January 1990 to December 2007 and comprising 668810 Holstein calving events from 2506 herds were included in the data set. First-parity cows represented $43.3 \%$, whereas second-, and third parities accounted for 33.4 and $23.3 \%$ of the calving records, respectively. The herds used in this study are among the purebred Holsteins which are managed under conditions similar to most other developed countries and are under official performance and pedigree recording. Stillbirth was defined as a calf dead at birth. Information for individual calving events, including herd, cow identification, service sire identification, cow's sire identification, birth date, calving date, dry date, parity, multiple births, and stillbirth were included in the data set. Stillbirth was coded as a dichotomous variable $(0=$ alive; $1=$ dead $)$. Only calving records from the first 3 parities were kept. Age at calving was between 20 and 40, 28 and 49, and 40 and 68 months in parities one, two, and three, respectively. Months of birth were grouped into four seasons: January through March (winter), April through June (spring), July through September (summer), and October through December (fall). In addition to the data file, a pedigree file was available that contained more than 497,000 cows, of which the first were born in 1963 (Table 1). The pedigree of animals was traced back for 5 generations. 
Vol. 20(2011): 287-297.

Table 1. Summary of pedigree information.

\begin{tabular}{lr}
\hline Animals in total & 497216 \\
Inbred animals & 208201 \\
Sires & 8007 \\
Dams & 242176 \\
Animals with progeny & 250183 \\
Animals without progeny & 247033 \\
Base animals & 87444 \\
Non-base animals & 409772 \\
\hline
\end{tabular}

\section{Statistical models for analysis}

Model specification and the choice of fixed effects to be considered was based on the backward elimination method. Also, the fit of all models was evaluated by using the Hosmer and Lemeshow goodness-of-fit test (Hosmer and Lemeshow 2000) of the LOGISTIC procedure of SAS (2002) by including the "lackfit" option in the model statement. Variables which were significant by the Wald statistic at $\mathrm{p}<$ 0.05 were included in the model. The final model included the fixed class effects of herd-year-season of calving, number of calves and the linear covariate effect of age at calving. The linear and threshold animal models were used with stillbirth defined as a dichotomous variable were as follows:

$\mathrm{y}=\mathrm{Xb}+\mathrm{Z}_{\mathrm{a}} \mathrm{a}+\mathrm{Z}_{\mathrm{m}} \mathrm{m}+\mathrm{e}$,

Where, $\mathrm{y}$ is a $\mathrm{N} \times 1$ vector of records, $\mathrm{b}$ denotes the fixed effects in the model with association matrix $\mathrm{X}$, a and $\mathrm{m}$ are the vectors of direct genetic and maternal genetic effects with the incidence matrixes $Z_{\mathrm{a}}$ and $\mathrm{Z}_{\mathrm{m}}$, respectively, and e denotes the vector of residual effects. In the threshold models, the observed outcome $\left(\mathrm{y}_{\mathrm{i}}\right)$ for calf $i$ is assumed to be ordered in 2 categories $(k=2)$ for stillbirth. An unknown liability $\left(\mathrm{U}_{\mathrm{i}}\right)$ with $k-1$ unknown thresholds $\left(\mathrm{t}=\left\{t_{1}, \ldots, t_{k-1}\right\}\right)$, which categorized the observed outcome. The (co)variance structure for the random effects was as follows:

$$
\begin{aligned}
& \mathrm{V}(\mathrm{a})=\mathrm{A} \sigma_{\mathrm{a}}^{2} \\
& \mathrm{~V}(\mathrm{~m})=\mathrm{A} \sigma_{\mathrm{m}}^{2} \\
& \mathrm{~V}(\mathrm{e})=\mathrm{I}_{\mathrm{n}} \sigma_{\mathrm{e}}^{2} \\
& \mathrm{Cov}(\mathrm{a}, \mathrm{m})=\mathrm{A} \sigma_{\mathbf{a}, \mathbf{m}},
\end{aligned}
$$

Where, $A$ is the additive numerator relationship matrix and $\sigma_{\mathrm{a}}{ }^{2}$ and $\sigma_{\mathrm{m}}{ }^{2}$ are additive direct and maternal variances, respectively. In addition, $\sigma_{\mathrm{a}, \mathrm{m}}$ and $\sigma_{e}{ }^{2}$ are direct-maternal covariance and residual variance, respectively. $\mathrm{I}_{\mathrm{n}}$ is identity matrix with order equal to the number of individual records. The linear and threshold sire models were defined as follows:

$\mathrm{y}=\mathrm{Xb}+\mathrm{Z}_{\mathrm{S}} \mathrm{s}+\mathrm{e}$

Where, $\mathrm{s}$ is the vector of sire effect with association matrix $Z_{S}$ and other terms are as defined above.

\section{Estimates of heritabilities and genetic trends}

Based on previous research the most parsimonious model for the analysis of a binomial variable, such as stillbirth, is a threshold model (Gianola 1982). The linear and threshold animal model analyses were run using a restricted maximum likelihood method and average information algorithm (AIREML) of the MATVEC program (Wang et al. 2001) to obtain (co)variance components and heritabilities of stillbirth in first, second, and third parities. Genetic trends were obtained by regressing yearly mean estimates of breeding values on calving year. Several linear-linear and threshold-threshold bivariate or pair-wise analyses were carried out for every pair of the traits (stillbirth in parities 1 with 2, 1 with 3 , or 2 with 3 ) to estimate genetic correlations for stillbirth in different parities. The models applied in pair-wise analyses were the same as those fitted for stillbirth rates of each parity in the univariate 
Ghavi Hossein-Zadeh, N. Genetic parameters for stillbirth in dairy cows

analyses. For sire models, the heritability estimates were calculated as:

$$
h^{2}=\frac{4 \sigma_{s}^{2}}{\sigma_{s}^{2}+\sigma_{e}^{2}},
$$

Where $4 \sigma_{\mathrm{S}}^{2}$ is the additive genetic variance and the denominator is the total phenotypic variance.

\section{Results}

Stillbirths accounted for $23.7 \%, 22.1 \%$ and $21.8 \%$ of total observations in first, second and third parities, respectively. The frequency of stillbirth decreased with parity. Phenotypic rates of stillbirth decreased from 1993 to 1998, for first, second and third calvings, and then increased from 1998 to 2007 for the first three parities (Fig. 1).

Estimates of heritabilities for stillbirth in first, second, and third parities by different animal and sire models are shown in Table 2. Estimates of genetic

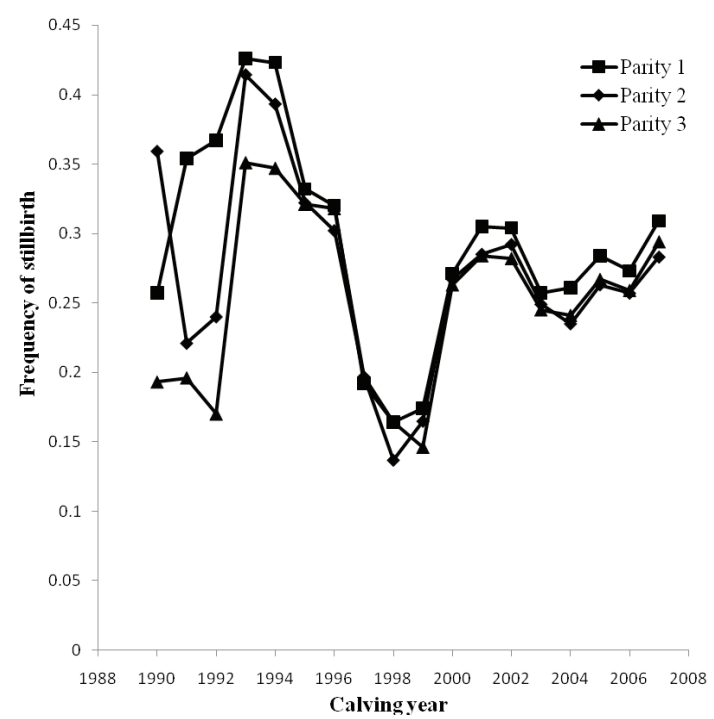

Fig 1. Phenotypic trend in the frequency of stillbirths by year of calving for first-, second-, and third-parity cows. trends and their standard errors for stillbirth at different parities from animal and sire models are shown in Tables 3 and 4, respectively. The mean

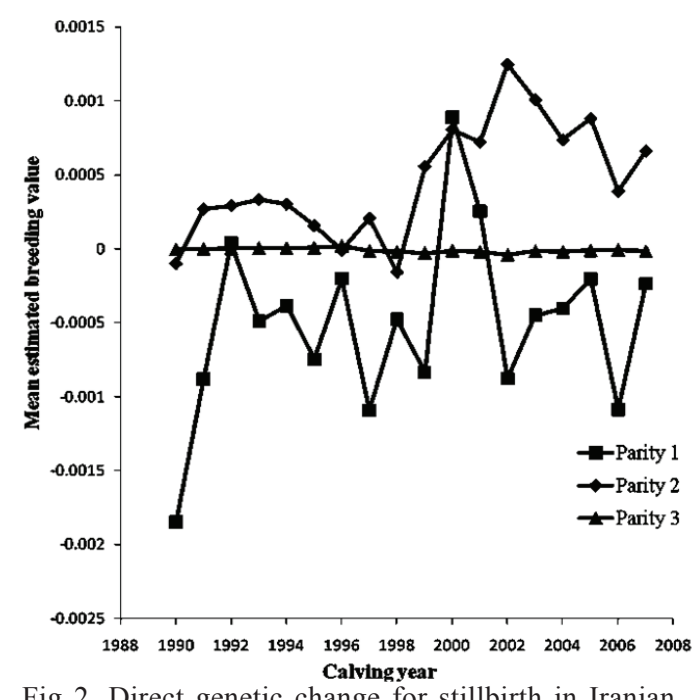

Fig 2. Direct genetic change for stillbirth in Iranian Holsteins by calving year obtained by linear animal model analysis for first-, second, and third parities.

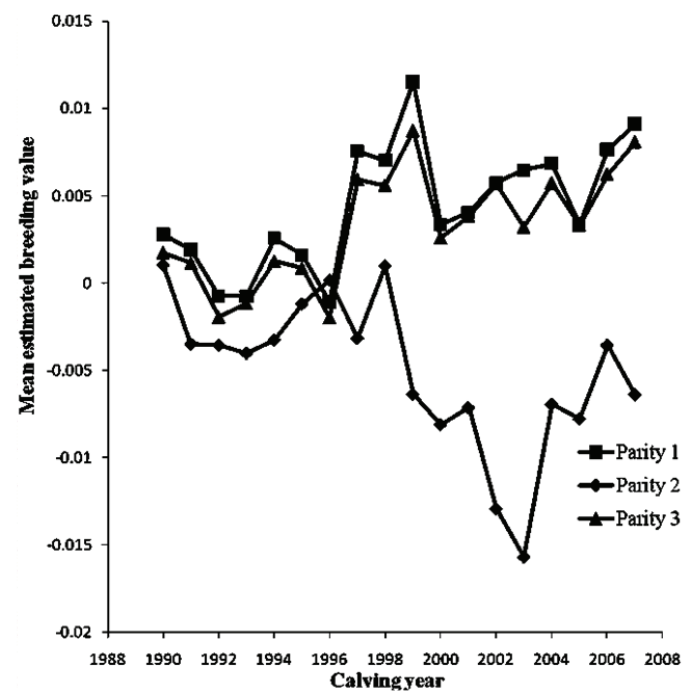

Fig 3. Direct genetic change for stillbirth in Iranian Holsteins by calving year obtained by threshold animal model analysis for first-, second, and third parities. 
Vol. 20(2011): 287-297.

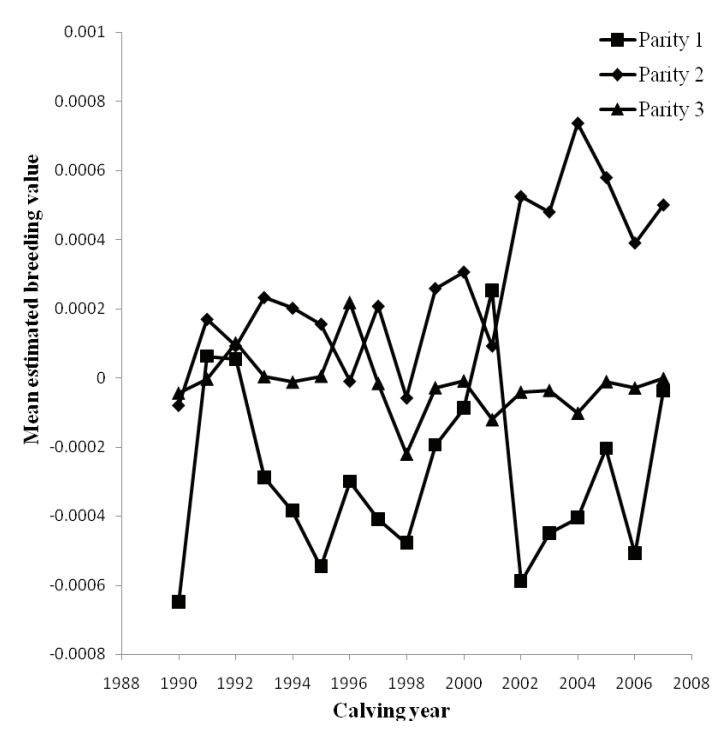

Fig. 4. Maternal genetic change for stillbirth in Iranian Holsteins by calving year obtained by linear animal model analysis for first-, second, and third parities.

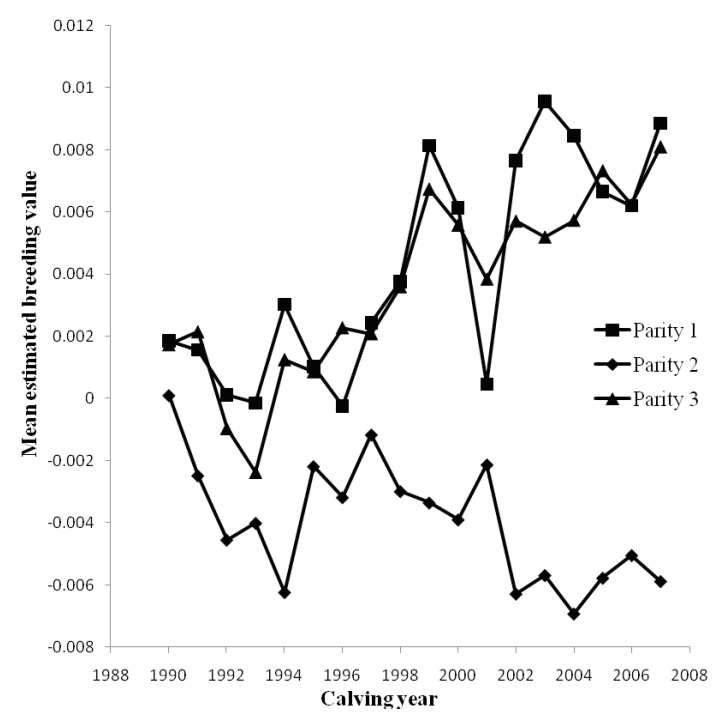

Fig. 5. Maternal genetic change for stillbirth in Iranian Holsteins by calving year obtained by threshold animal model analysis for first-, second, and third parities.

Table 3. Estimates of genetic trends and their standard errors $(\times 1000)$ for stillbirth at different parities from linear and threshold animal models.

Model of analysis

\begin{tabular}{llccc}
\hline & & \multicolumn{2}{c}{ Linear animal } & Threshold animal \\
\hline Parity & Direct trend & Maternal trend & Direct trend & Maternal trend \\
\hline 1 & $0.03 \pm 0.005^{*}$ & $0.0003 \pm 0.0001^{*}$ & $0.34 \pm 0.03^{*}$ & $0.42 \pm 0.03^{*}$ \\
2 & $0.05 \pm 0.003^{*}$ & $0.03 \pm 0.006^{*}$ & $-0.38 \pm 0.03^{*}$ & $-0.23 \pm 0.04^{*}$ \\
3 & $-0.0005 \pm 0.0002$ & $-0.004 \pm 0.0002$ & $0.25 \pm 0.04^{*}$ & $0.37 \pm 0.04^{*}$
\end{tabular}

* Significant coefficients are shown with asterisks $(\mathrm{p}<0.05)$

Table 4. Estimates of genetic trends and their standard errors $(\times 1000)$ for stillbirth at different parities from linear and threshold sire models.

\begin{tabular}{lcc}
\hline & \multicolumn{2}{c}{ Genetic trend* } \\
\hline Parity & Model of analysis \\
\hline 1 & Linear sire & Threshold sire \\
2 & $-0.02 \pm 0.003$ & $0.07 \pm 0.02$ \\
3 & $0.01 \pm 0.001$ & $-0.15 \pm 0.01$ \\
* All of the estimates were significant at $p<0.001$ & $0.04 \pm 0.01$
\end{tabular}


Ghavi Hossein-Zadeh, N. Genetic parameters for stillbirth in dairy cows

estimated breeding values of cows by year of calving are in Figures 2 to 5, using different animal models. Mean estimated breeding values of bulls by year of birth obtained by linear and threshold sire models are plotted in Figures 6 and 7, respectively. Heritability estimates for stillbirth, from the analysis by threshold models, were greater than the corresponding estimates from linear models. Also, heritability estimates were greater for stillbirth in the first parity than in second and third parities, using both linear and threshold models of analysis. The heritability estimates for stillbirth obtained from linear animal and linear sire models were similar. But estimates of threshold animal models were greater than the estimates of threshold sire models. The threshold animal model estimates of direct heritabilities for stillbirth in this study were 0.038 to 0.087 while estimates for the maternal heritabilities ranged from 0.020 to 0.067 . The linear model estimates of direct and maternal heritabilities for stillbirth in the current study were from 0.001 to 0.022 and from 0.0008 to 0.014 over the parities, respectively. The threshold sire model estimates of heritabilities for stillbirth in this study were 0.021 to 0.071 , while the linear sire model estimates of heritabilities for

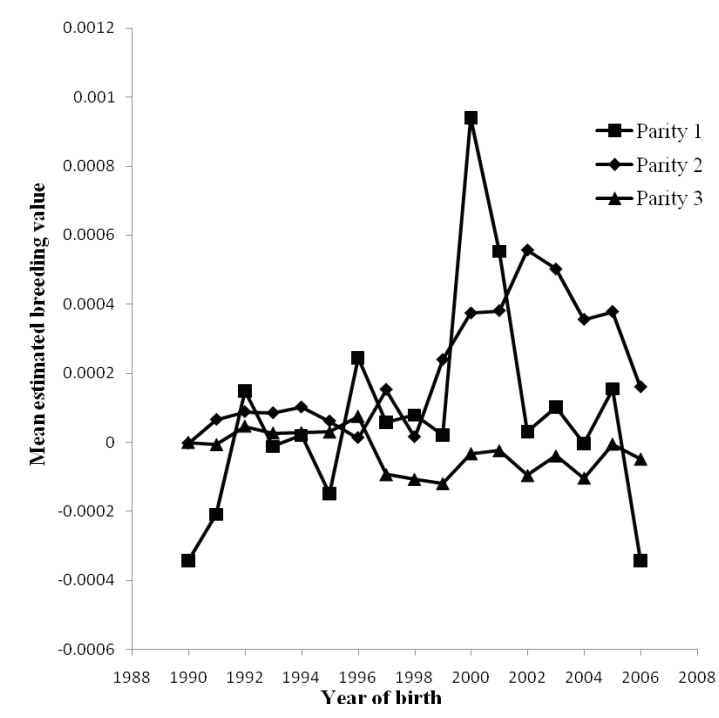

Fig. 6. Mean estimated breeding values by year of birth obtained by linear sire model analysis for first-, second, and third parity. stillbirth in the current study were from 0.003 to 0.021 over the parities.

There was slightly increasing trend for stillbirth rate in parities 1 and 2 over time with the analysis by linear animal and linear sire models, but, the direct and maternal trends of stillbirth rate in parity 3 from the analysis by linear models was not significant. There was a significant decreasing trend for stillbirth rate in parity 1 and 3 over time from the analysis by threshold animal and threshold sire models, but the genetic trend for stillbirth rate in parity 2 with these models of analysis was significantly positive. Therefore, the patterns of variation in genetic trends for stillbirth obtained from linear models were different from threshold models over the parities. Estimates of genetic correlation between direct and maternal effects for stillbirth in the present study were from -0.05 to $-0.02 \mathrm{ob}-$ tained by linear animal model and were from 0 to 0.04 obtained by threshold animal model over the parities. Direct and maternal genetic correlations for stillbirth between parities were respectively from 0.01 to 0.11 and -0.12 to 0.15 obtained by linear animal model and were from 0.03 to 0.12 and -0.35 to 0.22 obtained by threshold animal

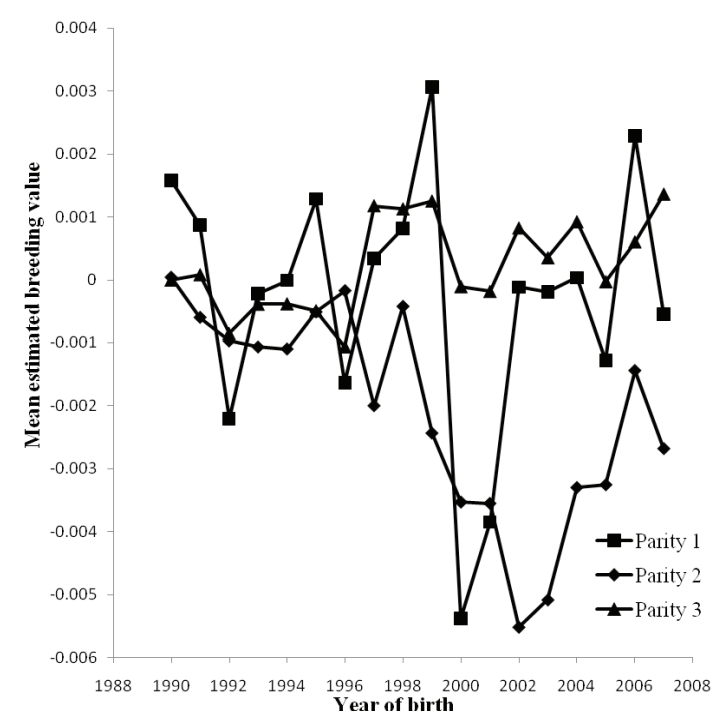

Fig. 7. Mean estimated breeding values of bulls by year of birth obtained by threshold sire model analysis for first-, second, and third parity. 
Vol. 20(2011): 287-297.

model, respectively (Table 5). In addition, estimates of genetic correlations for stillbirth between parities were from -0.01 to 0.10 obtained by linear sire models and were from 0.03 to 0.08 obtained by threshold sire models (Table 5).

Solutions for age at calving for parity 1,2 , and 3 demonstrated that cows younger at calving are more likely to have stillbirth. Also, solutions for

Table 5. Estimates of direct and maternal genetic correlations for stillbirth between parities 1, 2, and 3 with linear and threshold animal models.

\begin{tabular}{lllll}
\hline Model of analysis & Trait 1 & Trait 2 & $r_{g 12}{ }^{1}$ & $r_{m 12}^{2}$ \\
\hline \multirow{2}{*}{ Linear animal } & Parity 1 & Parity 2 & 0.01 & -0.06 \\
& Parity 1 & Parity 3 & 0.11 & 0.15 \\
Threshold animal & Parity 2 & Parity 3 & 0.11 & -0.12 \\
& Parity 1 & Parity 2 & 0.03 & -0.35 \\
\multirow{2}{*}{ Linear sire } & Parity 1 & Parity 3 & 0.08 & 0.22 \\
& Parity 2 & Parity 3 & 0.12 & -0.27 \\
Parity 1 & Parity 2 & -0.01 & - \\
Threshold sire & Parity 1 & Parity 3 & 0.10 & - \\
& Parity 2 & Parity 3 & 0.04 & - \\
& Parity 1 & Parity 2 & 0.03 & - \\
\hline
\end{tabular}

$\Gamma=$ Direct genetic correlation between trait 1 and trait 2

$2=$ Maternal genetic correlation between trait 1 and trait 2

Table 6. Solutions for fixed effects obtained from linear and threshold models.

\begin{tabular}{|c|c|c|c|c|c|}
\hline \multicolumn{6}{|c|}{ Model } \\
\hline Parity & Effect & Linear animal & $\begin{array}{c}\text { Threshold } \\
\text { animal }\end{array}$ & Linear sire & Threshold sire \\
\hline \multirow[t]{3}{*}{1} & Single & 0 & 0 & 0 & 0 \\
\hline & Twin & 0.06 & 0.09 & 0.06 & 0.09 \\
\hline & Age at calving & -0.0003 & -0.0005 & -0.0003 & -0.0004 \\
\hline \multirow[t]{3}{*}{2} & Single & 0 & 0 & 0 & 0 \\
\hline & Twin & 0.04 & 0.08 & 0.04 & 0.08 \\
\hline & Age at calving & -0.00003 & -0.00004 & -0.00003 & -0.00004 \\
\hline \multirow[t]{3}{*}{3} & Single & 0 & 0 & 0 & 0 \\
\hline & Twin & 0.04 & 0.05 & 0.04 & 0.05 \\
\hline & Age at calving & -0.0009 & -0.0006 & -0.0009 & -0.0006 \\
\hline
\end{tabular}


Ghavi Hossein-Zadeh, N. Genetic parameters for stillbirth in dairy cows

number of calves born demonstrated that twincalvers are more likely to have stillbirth (Table 6).

\section{Discussion}

The rate of stillbirth is highest for first-calving cows, partly because of a disproportion between the size of the calf and the size of the pelvic area (fetopelvic-complex), which causes a difficult calving (Meijering 1984). Consistent with the current results, Ghavi Hossein-Zadeh et al. (2008) and Steinbock et al. (2003) reported greater incidences of stillbirth in primiparous cows than in multiparous cows. The stillbirth frequencies for Holsteins in the current study were much greater than for other reports. These greater frequencies could be assigned to management or environmental factors in under study population. Heringstad et al. (2007) reported stillbirth rate was around 3\% for first calving, and $1.5 \%$ for second and later calvings in Norwegian Red. The stillbirth rate for first-calving Holstein cows in the United States increased from 9.5\% in 1985 to $13.2 \%$ in 1996 (Meyer et al. 2001a). Hansen et al. (2004b) found that the stillbirth frequency for first-calving Danish Holstein increased from 7\% in 1992 to $9 \%$ in 2002. Also, the stillbirth rate for Swedish Holstein heifers has increased over the past 10 to 15 year, and about $10 \%$ of the calves are born dead or die within the first $24 \mathrm{~h}$ (Steinbock et al. 2003). In Swedish Red there has been a slight increase in stillbirth frequency over the last 25 year, from less than 4 to around 5\% for heifers, and from 3 to $4.5 \%$ for Swedish Red cows (Philipsson et al. 2006). Cows younger at calving are more likely to have stillbirth and this might be related to the greater incidence of calving difficulty at younger ages especially for first-calvers. Consistent with the current results, Steinbock et al. (2003) reported age of the heifer at calving had a considerable impact on stillbirth and calving difficulty in dairy cows. Also, similar to the current results, Ghavi HosseinZadeh et al. (2008) reported the odds of stillbirth was greater after twin births, with $18.8 \%$ of the twin calving events reporting calves as dead compared to $4.0 \%$ for singleton births

The greater heritability estimates for stillbirth in the first parity were probably due to greater genetic variation of stillbirth in the first parity than in other parities. In animal models, all relationships are considered, whereas in sire models only relationships among sires are taken into account; this leads to some bias in estimates from sire models. Therefore, if selection intensity is stronger for males than for females, estimates from sire variances are expected to underestimate genetic variance. As a consequence, smaller estimates of heritability are obtained with sire than with animal models (Visscher and Thompson 1990). The threshold estimates of direct heritabilities for stillbirth in this study were generally consistent with other recent threshold model estimates ranging from 0.04 to 0.12 for heritability of stillbirth in dairy cows (Hansen et al. 2004a; Gevrekçi et al. 2006, Heringstad et al. 2007). Also, the threshold estimates of maternal heritabilities for stillbirth in the current study were generally lower than the reports of Heringstad et al. (2007), Gevrekçi et al. (2006) and Steinbock et al. (2003), but were consistent with the report of Cole et al. (2007) who reported the maternal heritability of stillbirth ranged from 0.046 to 0.065 . Similar to the current results, Fuerst-Waltl and Sørensen (2009), Heringstad et al. (2007), Jamrozik et al. (2005) and Luo et al. (1999) reported linear model estimates of heritability of stillbirth in general are lower than those obtained from threshold models. Ghavi Hossein-Zadeh et al. (2006) in a simulation study reported that the linear model has always underestimated true heritabilities, but threshold models did not show consistent trends. While threshold model may be trusted at higher levels of true heritability, it does not behave consistently at lower heritabilities. Heritability estimates of stillbirth rate, when analyzed with a linear model, depend on the frequency of the trait (Gianola 1982). It is, therefore, not straightforward to compare estimates from different populations. From studies using linear models, Luo et al. (1999), Harbers et al. (2000), and Meyer et al. (2001b) found heritabilities similar to this study. Also, consistent with the results of this study, Steinbock et al. (2006) reported the heritability 
Vol. 20(2011): 287-297.

of stillbirth on the observable scale was $0.7-1.3 \%$ in Swedish Red dairy cattle, using linear models of analysis. Estimates of direct heritabilities were greater than maternal ones and this would be due to greater effects of animals on the genetic variation of stillbirth in Iranian Holsteins than maternal effects.

Although there was no specific reason for phenotypic variations of stillbirth over the parities, but these would be likely related to the change in herd management, nutritional conditions or in general, changes in environmental variables affecting stillbirth rate. On the other hand, selection against stillbirth based on the first parity performance could be as a possible cause of decreasing phenotypic trends for stillbirth in the first and second parities. A possible explanation for the increasing genetic trend of stillbirth with some of the models may be the possible genetic association between stillbirth and some of the traits such as calving difficulty and calf size and an increase in the direct and maternal effects of these traits in the Holstein dairy cows of Iran. It seems that the observed increasing genetic trend (direct and maternal) for stillbirth rate with some of the models of analysis could be attributed to an intense use of Holstein-Friesian sires as sires of sons in Iran. Iranian Holsteins are either descendants of the cows originally imported from North America and Europe or Holstein upgrades of domestic breeds over 50 years. Therefore, these sires of sons have a large impact on the genetic trend, especially for the genetic trend of the AI bulls. Similar to the results of this study, Hansen et al. (2004b) reported an unfavorable genetic trend of stillbirth was found in Danish Holsteins. Also, in Holstein-Friesian in the US, indications of an unfavorable direct and maternal trends of stillbirth have been found (Meyer et al. 2001a), but contrary to the current results, no genetic trend was found in the Netherlands (Harbers et al. 2000). Also, Hansen et al. (2004b) found no maternal trend for stillbirth in Danish Holsteins. In addition, Heringstad et al. (2007) reported little or no genetic change in stillbirth at first calving in Norwegian Red dairy cattle. On the other hand, inconsistent with the results of this study, Cole et al. (2007) reported neither phenotypic nor genetic trends were significant for stillbirth in US Holsteins.
A correlation close to zero implies that selection on the direct effect of stillbirth would not influence the maternal effect of stillbirth. The present estimates are in agreement with the results of Cole et al. (2007), Hansen et al. (2004a), Luo et al. (1999) and Steinbock et al. (2003) who reported the mean genetic correlations between the direct and maternal effects of stillbirth were -0.02 , $0.03-0.06,0.03$ and -0.11 , respectively. However, contrary to the current results, Luo et al. (1999) reported the mean genetic correlation between the direct and maternal effects of stillbirth was -0.24 obtained by a linear model.

\section{Conclusions}

The frequency of stillbirth decreased with parity in Iranian Holstein dairy cows. Phenotypic rates of stillbirth decreased from 1993 to 1998, for first, second and third calvings, and then increased from 1998 to 2007 for the first three parities. The level of stillbirth is high in the Iranian Holsteins compared to other countries; therefore, there is a scope for the genetic improvement of this trait. Because of the economic and animal welfare issues, it is important to introduce the stillbirth in the national selection index used for selection of Holstein cows, as well as to avoid using animals that are extremely bad for this trait. Then, in populations with higher frequency of stillbirth such as Iranian Holsteins, more weight could be placed on stillbirth to avoid further deterioration. Heritability estimates for stillbirth, from the analysis by threshold models, were greater than the corresponding estimates from linear models. Also, heritability estimates were greater for stillbirth in the first parity than in second and third parities, using both linear and threshold models of analysis. The low estimates of heritability obtained in this study implied that much of the improvement in stillbirth could be attained by improvement of production environment rather than genetic selection. 


\section{References}

Abdel-Azim, G. A. \& Berger, P. J. 1999. Properties of threshold model predictions. Journal of Animal Science 77: 582-590.

Berger, P. J., Thompson, J. R. \& Sattler, C. G. 1998. Preliminary investigations on the feasibility of a stillbirth evaluation for the USA. Interbull Bulletin 18: 28-30.

Cole, J. B., Wiggans, G. R. \& Van Raden, P. M. 2007. Genetic evaluation of stillbirth in United States Holsteins using a sire-maternal grandsire threshold model. Journal of Dairy Science 90: 2480-2488.

Fuerst-Waltl, B. \& Sorensen, M. K. 2009. Genetic analysis of calf and heifer losses in Danish Holstein. Interbull Bulletin 40: 117-122.

Gevrekçi, Y., Y. Chang, M., Kızılkaya, K., Gianola, D., Weigel, K. A. \& Akbaş, Y. 2006. Bayesian inference for calving ease and stillbirth in Holsteins using a bivariate threshold sire-maternal grandsire model. In: Proceedings, 8th WCGALP, World Congress on Genetics Applied to Livestock Production, August, 13 to 18, 2006, Belo Horizonte, Minas Gerais, Brazil CDROM

Ghavi Hossein-Zadeh, N., Nejati-Javaremi, A., MiraeiAshtiani, S. R. \& Mehrabani-Yeganeh, H. 2006. Effect of threshold nature of traits on heritability estimates obtained by linear model. In: Proceedings, 8th WCGALP, World Congress on Genetics Applied to Livestock Production, August, 13 to 18, 2006, Belo Horizonte, Minas Gerais, Brazil. CDROM

Ghavi Hossein-Zadeh, N., Nejati-Javaremi, A., MiraeiAshtiani, S. R. \& Kohram, H. 2008. An observational analysis of twin births, calf stillbirth, calf sex ratio, and abortion in Iranian Holsteins. Journal of Dairy Science 91: 4198-4205.

Gianola, D. 1982. Theory and analysis of threshold characters. Journal of Animal Science 54: 1079-1096.

Gianola, D. \& Foulley, J. L. 1983. Sire evaluation for ordered categorical data with a threshold model. Genetics Selection Evolution 15: 201-224.

Gilmour, A. R., Anderson, R. D. \& Rae, A. C. 1985. The analysis of binomial data by a generalized linear mixed model. Biometrika 72: 593-606.

Hansen, M., Lund, M. S., Pedersen, J. \& Christensen, L. G. 2004a. Genetic parameters for stillbirth in Danish Holstein cows using a Bayesian threshold model. Journal of Dairy Science 87: 706-716.

Hansen, M., Misztal, I., Lund, M. S., Pedersen, J. \& Christensen, L. G. 2004b. Undesired phenotypic and genetic trend for stillbirth in Danish Holsteins. Journal of Dairy Science 87: 1477-1486.

Harbers, A., Segeren, L. \& de Jong, G. 2000. Genetic parameters for stillbirth in The Netherlands. Interbull Bulletin 25: 117-122.

Harville, D. A. \& Mee, R. W. 1984. A mixed-model procedure for analyzing ordered categorical data. Biometrics 40: 393-408.

Heringstad, B., Chang, Y. M., Svendsen, M. \& Gianola, D. 2007. Genetic analysis of calving difficulty and stillbirth in Norwegian Red cows. Journal of Dairy Science 90: 3500-3507.

Hosmer, D. \& Lemeshow, S. 2000. Applied Logistic Re- gression. 2nd ed. Wiley-Interscience, New York: John Wiley \& Sons. $373 \mathrm{p}$.

Jamrozik, J., Fatehi, J., Kistemaker, G. J. \& Schaeffer, L. R. 2005. Estimates of genetic parameters for Canadian Holstein female reproduction traits. Journal of Dairy Science 88: 2199-2208.

Luo, M. F. 1999. Bayesian inference for calving ease and stillbirth in dairy cattle. Ph.D. Diss. Univ. Guelph, Canada.

Luo, M. F., Boettcher, P. J., Dekkers, J. C. M. \& Schaeffer, L. R. 1999. Bayesian analysis for estimation of genetic parameters of calving ease and stillbirth for Canadian Holsteins. Journal of Dairy Science 82: 1848-1858.

Meijering, A. 1984. Dystocia and stillbirths in cattle-A review of causes, relations and implications. Livestock Production Science 11: 143-176.

Meyer, C. L., Berger, P. J., Koehler, K. J., Thompson, J. R. \& Sattler, C. G. 2001a. Phenotypic trends in incidence of stillbirth for Holsteins in the United States. Journal of Dairy Science 84: 515-523.

Meyer, C. L., Berger, P. J., Thompson, J. R. \& Sattler, C. G. 2001b. Genetic evaluation of Holstein sires and maternal grandsires in the United States for perinatal survival. Journal of Dairy Science 84: 1246-1254.

Nielsen, L. A. H., Glacius, A., Fogh, A. \& Skjøth, F. 2002. Dødelighed hos kalve af malkerace. Rep. No. 102. Danish Cattle, Udkærsvej 15, Aarhus, Denmark.

Philipsson, J. 1976. Studies on calving difficulty, stillbirth, and associated factors in Swedish cattle breeds. I. General introduction and breed averages. Acta Agriculturae Scandinivica 26: 151-164.

Philipsson, J., Foulley, J. L., Lederer, J., Liboriussen, T. \& Osinga, A. 1979. Sire evaluation standards and breeding strategies for limiting dystocia and stillbirth. Report of an EEC/EAAP Working Group. Livestock Production Science 6: 111-127.

Philipsson, J., Steinbock, L. \& Johansson, K. 2006. Differences in genetic variation of calving traits in Swedish Holstein and Swedish Red cattle. In: Proceedings, 8th WCGALP, World Congress on Genetics Applied to Livestock Production, August, 13 to 18, 2006, Belo Horizonte, Minas Gerais, Brazil. CDROM

Rossoni, A., Nicoletti, C., Ghiroldi, S., Santus, E. \& Bagnato, A. 2005. Calf's suckling ability in Italian Brown Swiss. Interbull Bulletin 33: 218-221.

Shook, G. E. 1998. Calfhood disease: an assessment.In: Proceedings 6th WCGALP, January 11-16, 1998, Armidale, Australia.

Steinbock, L., Näsholm, A., Berglund, B., Johansson, K. \& Philipsson, J. 2003. Genetic effects on stillbirth and calving difficulty in Swedish Holsteins at first and second calving. Journal of Dairy Science 86: 2228-2235.

Steinbock, L., Johansson, K., Näsholm, A., Berglund, B. \& Philipsson, J. 2006. Genetic effects on stillbirth and calving difficulty in Swedish Red dairy cattle at first and second calving. Acta Agriculturae Scandinivica 56(2): 65-72.

Thompson, J. R., Freeman, A. E., Berger, P. J. \& Martinez, M. L. 1981. A survey of dystocia and calf mortality in five dairy breeds. Journal of Dairy Science 64 (Suppl. 1): 81. (Abstr.)

Visscher, P. M. \& Thompson, R. 1990. REML estimates of parameters for fat yield in pedigree herds in the UK. Using an individual animal model; male and female herita- 
Vol. 20(2011): 287-297.

bility estimates. In: Proceedings 4th WCGALP Congress on Genetics Applied to Livestock Production, September 10-14, 1990 Edinburgh, Scotland XIV: 233.

Wang, T., Fernando, R. I. \& Kachman, D. S. 2001. MATVEC user's guide.

Weller, J. I., Misztal, I. \& Gianola, D. 1988. Genetic analysis of dystocia and calf mortality in Israeli-Holsteins by threshold and linear models. Journal of Dairy Science 71: 2491-2501.

Wright, S. 1934. An analysis of variability in number of digits in an inbred strain of guinea pigs. Genetics 19: 506-536. 